\title{
PROPOSIC̣̃̃ES DE INOVAC̣ÃO DIDÁTICA NA PERSPECTIVA DOS TRÊS MOMENTOS PEDAGÓGICOS: TENSÕES DE UM PROCESSO FORMATIVO
}

\author{
Josyane Barros Abreu* \\ Nadia Magalhães da Silva Freitas**
}

RESUMO: Diante de uma conjuntura de renovações, métodos e estratégias que intenciona reinventar a prática docente, objetivamos compreender tensões e possibilidades relacionadas à inovação didática. Apostamos na proposta dos Três Momentos Pedagógicos. A investigação caracterizou-se como de abordagem qualitativa, precisamente uma pesquisa-formação, no contexto de uma licenciatura da Universidade Federal do Pará. No processo formativo, os sujeitos manifestaram dificuldades em problematizar um tema, resistências em abandonar aulas tradicionais e dificuldades em superar as amarras de uma avaliação pontual e finalística. Entendemos tais dificuldades como herança de uma formação docente vivida ainda quando alunos. No entanto, a experiência configurou-se uma autêntica problematização da docência, com potencial para superar e romper entraves enraizados em nós, possibilitando a (re)construção de significados relacionados ao "saber fazer" e ao "saber ser" professor.

Palavras-chave: Formação de professores. Três Momentos Pedagógicos. Inovação.

\section{PROPOSICIONES DE INNOVACIÓN DIDÁCTICA EN LA PERSPECTIVA DE LOS TRES MOMENTOS PEDAGÓGICOS: TENSIONES DE UN PROCESO FORMATIVO RESUMEN:}

Frente a una coyuntura de renovaciones, métodos y estrategias que tiene la intención de reinventar la práctica docente, tenemos el objetivo de comprender tensiones y posibilidades relacionadas a la innovación didáctica. Apostamos en la propuesta de los Tres Momentos Pedagógicos. La investigación se caracterizó como de enfoque cualitativo, específicamente una investigación-formación, en el contexto de una licenciatura de Universidade Federal do Pará. En el proceso formativo, los sujetos manifiestan dificultades para problematizar un tema, resistencias para abandonar clases tradicionales y dificultades para superar las amarras de una evaluación puntual y finalística. Comprendemos tales dificultades como una herencia de una formación docente vivida aun cuando eran alumnos. Sin embargo, la experiencia se configuró como una auténtica problematización

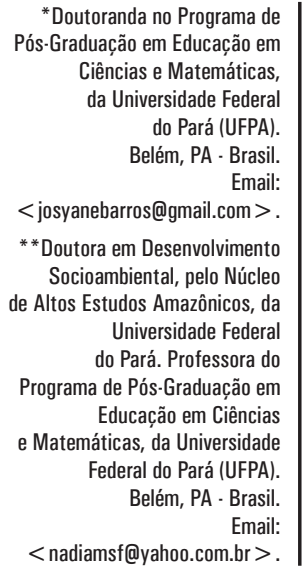


de la docencia, con un potencial para superar y romper obstáculos arraigados en nosotros, lo que posibilitó la (re)construcción de significados relacionados al "saber hacer" y al "saber ser" profesor. Palabras -clave: Formación de profesores. Tres Momentos Pedagógicos. Innovación.

PROPOSITIONS OF DIDACTIC INNOVATION IN THE PERSPECTIVE OF THE THREE PEDAGOGICAL MOMENTS: TENSIONS OF A FORMATIVE PROCESS

ABSTRACT: In the face of a conjuncture of renewals, methods, strategies that intend to reinvent the teaching practice, we aimed to understand, through the Three Pedagogic Moments, the tensions and the possibilities related to didactic innovation. The research was characterized as a qualitative approach, precisely a research-training in the context of a Bachelor's Degree from the Federal University of Pará. In the training process, the individuals haves expressed difficulties in problematize a theme, resistance to abandon traditional lessons and difficulties in overcoming a punctual and finalistic evaluation. We understand these difficulties as inheritance of a teacher formation lived even when students. The experience was an authentic problematization of teaching, with the potential to overcome and to break barriers, making possible to (re) construct meanings related to the "know how to do" and "how to be" a teacher.

Keywords: Teacher training. Three Pedagogic Moments. Innovation. 


\section{INTRODUÇÃO}

Atualmente há uma conjuntura de renovações, métodos, estratégias, recursos, entre outros, que têm sido elaborados e experimentados na intenção de reinventar a prática pedagógica dos professores e, assim, dar mais sentido à educação, em particular à educação em ciências. No entanto, percebemos que a ambiência de sala de aula não tem se constituído, por vezes, espaço de criação, inovação e transformação de práticas educacionais (MATOS, 2010), notadamente no que se refere ao atendimento das necessidades formativas para o presente século, no sentido de religar saberes (MORIN, 2001), por exemplo.

Gentilini e Scarlatto $(2015$, p.15) ponderam que "[...] não é raro ouvir que as escolas estão no século XIX, os professores no século XX e os alunos no século XXI", o que muito nos chama atenção. Pode haver exagero na afirmativa dos autores, mas não há que considerá-la de toda insana. Em algumas situações fica perceptível que nós professores não somos preparados para enfrentar as anomalias que o sistema educacional apresenta, o que deve ter relação com o passo desarmônico com que caminha a formação inicial, a realidade da educação e da escola (GENTILINI; SCARLATTO, 2015).

Diante disso, percebemos um cenário de desinteresse dos alunos pela ciência divulgada nas escolas brasileiras, notadamente ao considerarmos que a mesma tem sido construída como um monólogo, incorporando características de uma ciência asséptica, apolítica (CHASSOT, 2011) e, acrescentamos a-histórica, monocromática, sedimentada, divorciada da experiência de vida do aluno; além de ser transmitida por "[...] visões empobrecidas e distorcidas que criam o desinteresse, quando não a rejeição de muitos estudantes e se convertem num obstáculo para a aprendizagem" (CACHAPUZ; GIL-PEREZ, 2011, p. 38).

Assim como nos séculos passados, a escola de hoje é saturada pela informação (CHASSOT, 2011). O fato é que em velocidade quase instantânea, temos na internet, redes sociais, jornais, bibliotecas eletrônicas, entre outros, o bombardeamento de informações atualizadas. Logo, não parece ser interessante ao aluno ter a escola como fonte de informação, visto que esta é facilmente acessada por aparatos tecnológicos amplamente disponíveis.

A concepção positivista, que ainda impregna os atos de ensinar e de aprender, reforça a divulgação de uma ciência carregada de conceitos e de fatos que compõem leis científicas desconexas da realidade que nos circunda (POZO; CRESPO, 2009). Pregar conhecimentos científicos que não têm significados ao contexto do aluno é contribuir para o entendimento de que

[...] aprender ciências é simplesmente repetir conhecimentos ditados pelo professor, e que o domínio da leitura e da escrita é critério para a aprendizagem de ciências, ou seja, sujeitos que não dominam a língua materna, ou que estão no início da sua aprendizagem não têm condições de aprender ciências (VIECHENESKI; LORENZETTI; CARLETTO, 2012, p. 862). 
É nesse contexto, que, por vezes, o processo de ensino e de aprendizagem limita-se ao desenvolvimento de capacidades cognitivas restritas à memorização e à reprodução de conteúdos científicos, como se os alunos fossem fotocópias vivas, capazes de repetir com exatidão aquilo que lhes foi passado (POZO; CRESPO, 2009). Entretanto, conhecimento não é uma réplica da realidade, e tão pouco nossos alunos são máquinas capazes de reproduzir literalmente tudo que é visto e ouvido nas salas de aula.

Em decorrência dos pontos elencados, temos um cenário no qual

[...] os alunos adotam atitudes inadequadas ou mesmo incompatíveis com os próprios fins da ciência, que se traduz em uma falta de motivação e interesse pela aprendizagem dessa disciplina, além de uma escassa valorização de seus saberes (POZO; CRESPO, 2009, p.17).

Podemos pensar que, de certo modo, isso seja reflexo da formação docente vivida nas universidades, as quais não acompanharam as mudanças educacionais no ritmo esperado, mantendo, assim, características fortes do paradigma tradicional de ensino (GENTILINI; SCARLATTO, 2015). Diante disso, entendemos como Kuhn (2011, p. 105) que se instala um momento de tensão, o qual “[...] consiste exatamente no fato de que indica que é chegada ocasião para renovar os instrumentos"; logo, precisamos despertar e abandonar os velhos hábitos formadores, para dar espaço a uma formação que contemple inovações necessárias aos tempos atuais, permitindo, assim, dar mais sentido ao aprender e ao ensinar.

Falando de inovação, entendemos esta como sendo "[...] estratégias que expressam dinâmicas explícitas com intenção de alterar ideias, concepções, conteúdos e práticas em alguma direção renovadora em relação à existente" (FARIAS, 2006, p. 43). Inclusive, podendo ser abandonada ou cancelada se assim for necessário, conforme aponta Farias (2006).

Nesse contexto, nos aproximamos da proposta didática dos Três Momentos Pedagógicos (3 MPs) - Problematização Inicial, Organização do Conhecimento e Aplicação do Conhecimento - (DELIZOICOV; ANGOTTI, 1990; DELIZOICOV; ANGOTTI; PERNAMBUCO, 2002; 2009), com a intenção de agregar proposições que caminham para uma perspectiva inovadora, que pontuamos mais adiante. Segundo Muenchen e Delizoicov (2014, p. 620, destaque do autor), os 3 MPs estão assim estruturados:

Problematização Inicial: apresentam-se questões ou situações reais que os alunos conhecem e presenciam e que estão envolvidas nos temas. Nesse momento pedagógico, os alunos são desafiados a expor o que pensam sobre as situações, a fim de que o professor possa ir conhecendo o que eles pensam. Para os autores, a finalidade desse momento é propiciar um distanciamento crítico do aluno ao se defrontar com as interpretações das situações propostas para discussão, e fazer com que ele sinta a necessidade da aquisição de outros conhecimentos que ainda não detém.

Organização do Conhecimento: momento em que, sob a orientação do professor, os conhecimentos [...] [científicos] necessários para a compreensão dos temas e da problematização inicial são estudados. 


\begin{abstract}
Aplicação do Conhecimento: momento que se destina a abordar sistematicamente o conhecimento incorporado pelo aluno, para analisar e interpretar tanto as situações iniciais que determinaram seu estudo quanto outras que, embora não estejam diretamente ligadas ao momento inicial, possam ser compreendidas pelo mesmo conhecimento.
\end{abstract}

No contexto de sua criação, a proposta didática dos 3 MPs foi chamada de Roteiro Pedagógico (RP) (DELIZOICOV, 1991). Na sua versão original, o RP não se fundamentava nas concepções educacionais de Paulo Freire. É com Delizoicov e Angotti que a proposta ganha uma nova roupagem, aproximando-se dos ideais freirianos (MUENCHEN, 2010).

Obras desenvolvidas por integrantes do Instituto de Física da Universidade de São Paulo foram também muito importantes para a legitimação e a divulgação da proposta didática dos 3 MPs, como os livros "Física" e "Metodologia do Ensino de Ciências", ambos publicados no ano de 1990, por Delizoicov e Angotti; e, também, a obra "Ensino de Ciências: fundamentos e métodos", publicada em 2002 por Delizoicov, Angotti e Pernambuco (MUENCHEN; DELIZOICOV, 2014).

Atentamos que é na perspectiva não cristalizada da versão original dos 3 MPs que desenvolvemos a pesquisa, intencionando alcançar uma apreensão multidimensional e inovadora de cada MP. Assim, ousamos fazer proposições à proposta dos 3MPs, por também compreender inovação como "[...] tentativas de mudanças conscientes e intencionalmente efetivadas, com o propósito de melhorar ou até modificar o sistema vigente" (MATOS, 2010, p. 38).

Pontuamos ainda que não é intenção deste trabalho destacar os 3 MPs como mais uma receita prodigiosa no campo da didática, mas, sim, explorá-lo como desafio e motivação para pensar sobre que ideias, crenças e valores revelam resistências ligadas à inovação didática para formação de professores das séries iniciais. É nesse contexto, que buscamos respostas para a seguinte inquietação: que tensões emergem de uma experiência formativa, mediada pela proposta didática dos $3 \mathrm{MPs}$, cuja perspectiva se propõe inovadora, no contexto de formação inicial de professores?

\title{
ENCAMINHAMENTOS METODOLÓGICOS DA PESQUISA
}

A pesquisa ora apresentada foi realizada em consonância com princípios da abordagem qualitativa, cujas possibilidades referem-se à compreensão da realidade e do mundo dos significados (MINAYO, 2016). No contexto aqui adotado, configura-se como uma pesquisa-formação, na qual os sujeitos em formação

[...] construirão seu relato com base numa série de etapas, alternando trabalho individual e trabalho em grupo. A reflexão sobre os processos de formação só é produtiva na medida em que os participantes se investem em cada etapa do trabalho, por si próprios bem como nas interações e transações que o grupo oferece (JOSSO, 2010, p. 71).

A pesquisa-formação é uma abordagem investigativa que "[...] contribui para a formação dos participantes no plano das aprendizagens reflexivas e interpretativas e toma lugar no seu percurso de vida [...]" (JOSSO, 2010, p. 71). 
O contexto da pesquisa se deu no Curso de Licenciatura Integrada em Educação em Ciências, Matemática e Linguagens (doravante Curso), do Instituto de Educação Matemática e Científica, da Universidade Federal do Pará. O Curso apresenta uma proposta diferenciada; e, neste sentido, busca desenvolver processos formativos que integram conhecimentos específicos e pedagógicos dos conteúdos, valorizando o pensamento complexo e a religação de saberes (FRAHIA-MARTINS, 2014).

Cabe destacar que o Curso fundamenta-se em “[...] princípios relevantes e significativos para a realização da docência qualificada de futuros professores dos anos inicias do ensino fundamental" (PROJETO, 2012, p. 19). Trata-se do estímulo à sensibilidade, à construção da autonomia, ao desenvolvimento da criatividade e dos princípios didático-pedagógicos (PROJETO, 2012). A estruturação curricular do Curso esquiva-se da centralidade e da supervalorização de conteúdos, organizandose em Eixos Temáticos ${ }^{1}$, não disciplinares. Neste ponto, destacamos que o tema "Estágios Temáticos de Alfabetização, Ciência Humanas (História e Geografia), Ciências e Matemática em situações reais ou simuladas I (Ciências) 2", constituiu-se o contexto da presente pesquisa, o qual ocorre no terceiro semestre do Curso.

No processo de investigação, acompanhamos o desenvolvimento do tema em uma turma do vespertino, constituída por 22 licenciandos, os quais se diferenciavam em histórias de vida, idades, motivações, objetivos, dificuldades, formação etc. Esses sujeitos são identificados no texto com nomes fictícios, na intenção de mantê-los em anonimato.

Para a realização da pesquisa, promovemos uma "experimentação", no que se refere ao desenvolvimento de roteiros de aulas, estruturado nos 3 MPs, com a perspectiva de criar um espaço de vivências e aprendizagens inovadoras do fazer docente, na condução de temas/conteúdos, estratégias, metodologias, em aproximação aos contextos e as realidades experimentadas pelos estudantes no seu dia a dia, entre outros aspectos. O processo formativo, propriamente dito, foi estruturado em três etapas, sendo elas: Apropriação, Construção do Roteiro de Aulas e Socialização.

Iniciando a pesquisa-formação, a etapa de Apropriação foi desenvolvida em cinco encontros, nos quais apresentamos aos alunos a proposta dos 3 MPs, mediada por leituras, análises, pesquisa e discussões de textos; além de estudos relativos aos seguintes assuntos: objetivos do ensino de ciências para os primeiros anos da educação básica, problemas e problematizações no ensino de ciências, estratégias e recursos para o ensino de ciências e estrutura de planejamento de ensino.

Já conhecida a proposta dos 3 MPs pelos alunos, seguimos para a etapa da Construção do Roteiro de Aulas. Os alunos foram organizados em sete equipes com a intenção de construir roteiros de aulas para os $1^{\circ}, 2^{\circ}, 3^{\circ}$, $4^{\circ}$ e $5^{\circ}$ anos do ensino fundamental e $1^{\circ}$ e $2^{\circ}$ etapa da Educação de Jovens e Adultos (EJA). A partir de uma ementa descritiva, construída por nós, os alunos foram desenvolvendo o planejamento em reuniões com suas equipes, sob nossa orientação. Nesses instantes, os alunos apresentavam suas ideias e constructos para cada MP e, a partir destes, discutimos as possibilidades de inovação, segundo nossa compreensão, nos seguintes termos: 
- Problematização Inicial: contemplar situações reais que os alunos conhecem; apresentar questões que não se restrinjam às perguntas diretivas, as quais exigem dos alunos apenas memorização e reprodução de conhecimentos; mas devem servir de questionamentos com potenciais para provocar no aluno uma curiosidade epistemológica; deve ser composta de um questionamento maior, que intitulamos aqui como "pergunta problematizadora", que permitisse múltiplos desdobramentos, que são questionamentos mais específicos.

- Organização do Conhecimento: fazer uso da diversidade de estratégias metodológicas; contemplar a construção de conhecimentos para além dos conteúdos conceituais, valorizando os procedimentais e atitudinais do tema proposto; contemplar atividades que promovam interação aluno-aluno e aluno-professor e que possibilitem o desenvolvimento da autonomia dos alunos na construção do conhecimento.

- Aplicação do Conhecimento: valorizar atividades que se afastem de um modelo pontual e finalístico de avaliação; contemplar propostas de tomada de decisão, valorizando multiplicidade de estratégia (estudo de caso, debate, carta aberta) e outras atividades mais complexas.

Assim, na etapa de Socialização, os alunos apresentaram os roteiros produzidos. $\mathrm{Na}$ oportunidade, eram feitas ponderações das formadoras e também dos outros alunos, o que possibilitou uma discussão ampliada sobre as possibilidades e os limites de cada MP, evidenciados nos roteiros.

Os encontros ocorridos nas etapas da pesquisa-formação foram todos audiogravados, registrados no diário de campo das pesquisadoras e, também, registrados nos diários de formação dos alunos. Além desses, utilizamos como instrumentos de coleta de dados um questionário com questões abertas, que norteou uma entrevista semiestruturada. A triangulação dos dados nos permitiu estabelecer as categorias emergentes, na apreensão das dificuldades e das resistências que incidiram ao longo do processo formativo, sendo elas: "dificuldades de um pensar complexo", "amarras de uma visão simplista do ensino de ciências" e "heranças de um avaliar pontual e finalístico".

Cabe destacar, neste ponto, que os alunos participantes da pesquisa assinaram o Termo de Consentimento Livre e Esclarecido (TCLE). Nele constavam objetivos, metodologia, benefícios e possíveis riscos da pesquisa para os mesmos. Também realizamos os devidos esclarecimentos sobre dúvidas da pesquisa quando manifestadas pelos alunos.

Os dados coletados foram organizados e analisados mediante Análise Textual Discursiva (ATD). Segundo Moraes e Galiazzi (2011, p. 7), "[...] corresponde a uma metodologia de análise de dados e informações de natureza qualitativa com a finalidade de produzir novas compreensões sobre os fenômenos e discursos". A ATD “[...] trabalha com textos, podendo partir de materiais já existentes ou esses podem ser produzidos dentro da própria pesquisa" (MORAES, 2007, p. 87). 


\section{TENSÕES EMERGENTES}

Reconhecemos que as experiências vividas se configuraram inovadoras ao considerarmos que a "[...] condição básica para se produzir uma inovação é: incorporar algo que até então não fazia parte da unidade de referência, alterando-a" (FARIAS, 2006, p. 52), assim como vivido nesse processo formativo, ancorado nos 3 MPs. No entanto, a incerteza mostrou-se uma fiel e inseparável companheira no trajeto desta investigação.

As etapas iniciais da pesquisa instituíram um universo conflitivo. Aparentemente não havia segredo: os alunos se envolveriam na proposta e, juntos, teríamos uma experiência formativa exitosa. Entretanto, do contexto de formação emergiram tensões, dificuldades e resistências que desenharam uma experiência desafiadora.

Foi buscando compreender esse processo, que nos deparamos com as ideias de Morin (2001, p. 202), quais sejam:

Um universo estritamente determinista, que fosse apenas ordem, seria um universo sem devir, sem inovação, sem criação; um universo que fosse apenas desordem, entretanto, não conseguiria constituir organização, sendo, portanto, incapaz de conservar a novidade e, por conseguinte, a evolução e o desenvolvimento. Um mundo absolutamente determinado, tanto quanto um completamente aleatório, é pobre e mutilado; o primeiro, incapaz de evoluir, e o segundo, de nascer.

Tais questões nos permitiram enxergar as possibilidades de trabalhar com a incerteza, estimulando o pensamento complexo, fomentando o pensar aventureiro, incentivando o autoexame e a tentativa de autocrítica (MORIN, 2001). Dessa forma, ancoramo-nos nas ideias de Morin, no sentido de reconhecer que a complexidade "[...] é aquilo que tenta conceber a articulação, a identidade e a diferença de todos os aspectos físicos, biológicos, sociais, culturais, psíquicos e espirituais de nós enquanto seres [...]" (MORIN, 2001, p. 175).

Foi partindo dessas apreensões que conseguimos compreender melhor as tensões vivenciadas no processo formativo. E mais, percebemos que as mesmas são importantes e necessárias para o movimento de criação e de recriação de ideias, práticas, posturas e identidades docentes. Assim, para melhor apresentação dos resultados, optamos por estruturá-los segundo as categorias emergentes na análise dos dados constituídos, em cada um dos 3 MPs.

\section{PROBLEMATIZAC̣ÃO INICIAL: DIFICULDADES DE UM “PENSAR COMPLEXO”}

Como já mencionado, o primeiro contato dos licenciandos com os 3 MPs se deu na etapa de Apropriação, e foi nessa fase que as primeiras discussões sobre a problematização aconteceram, mediadas por estudos dos trabalhos de Delizoicov (2002), Marengão (2012) e Muenchen e Delizoicov (2014) e, também, as primeiras tensões. Já na etapa de Construção dos Roteiros de Aulas, quando convidados a desenvolver a problematização do tema proposto, muitos licenciandos manifestaram dificuldades, de diversas ordens. Apresento algumas delas nos excertos a seguir: 
O problema estava justamente nesta etapa! Como problematizar? Esta foi a pergunta que caminhou conosco no decorrer do trabalho. [...]. Saber problematizar a ponto de tornar o assunto instigante e curioso para o aluno não é nada fácil (TAIANA);

Ao iniciar o processo de construção do conhecimento, sobre os três momentos pedagógicos, logo no início tive grandes dificuldades para compreender a problematização inicial, não conseguia formular uma questão problematizadora, e assim foi por muito tempo, quando precisei fazer mais questões achei bem pior e difícil. [...] As dificuldades de formular as questões problematizadoras são grandes, pois tentar formular esta questão de maneira que não seja diretiva, torna-se mais complicado (LÚCIA);

No início das aulas foi bem difícil entender o que era essa pergunta problematizadora, pois sempre que entregávamos a pergunta, estava diretiva; depois de muitas aulas e muitas insistências, fomos começando a ter noção do que era problematização, mas antes disso, essa primeira parte virou um problema (MARTA).

Como visto, é recorrente na fala dos sujeitos o impasse em elaborar uma problematização. Junto com as dificuldades, os alunos também se sentiram inseridos em um campo de incertezas. Resultado semelhante foi levantado na pesquisa de Muenchen e Delizoicov (2013), que entrevistam cinco professores/formadores que desenvolveram atividades na formação inicial e continuada, envolvendo problematização, os quais relataram ser um desafio construir questões que tenham efeito problematizador.

As dúvidas e as divergências expressas pelos alunos são questões comuns, com as quais os profissionais da educação convivem cotidianamente e, por isto, precisam enfrentá-las. Isso porque, diariamente, somos bombardeados por problemas complexos, de natureza ambiental, ética, política, entre outras. Mas, como nos diz Cachapuz, Carvalho e Gil-Pérez (2012), não cabe a nós sermos peritos em tudo. Entretanto, precisamos compreender minimamente tais problemas. Assim, as necessidades educativas atuais passam a exigir um exercício mais complexo dos professores, também no sentido de que estes proporcionem aos seus alunos experiências que os façam refletir sobre tais questões.

Nesse viés, concordamos com Santos, Silva e Araújo (2012) ao afirmarem que enquanto professor, valorizar a contradição, o questionamento e a interrogação das certezas e incertezas, é possibilitar a compreensão de conhecimentos não mais fragmentados e compartimentalizados que explicam os fenômenos que nos rodeiam; pelo contrário, é uma incitação ao pensamento multidimensional (MORIN, 2001). O movimento de problematização é direcionado para além da abordagem conceitual, visando à inter-relação dos conteúdos que os alunos conhecem e presenciam no seu dia a dia (DELIZOICOV; ANGOTTI; PERNAMBUCO, 2009), como os relacionados ao fazer e ao ser.

$\mathrm{Na}$ afirmativa de Rosa, Perez e Drum (2007), alguns professores, notadamente os que lecionam nos primeiros ciclos de ensino básico, estão fortemente vinculados a um currículo que aprecia mais os conhecimentos linguísticos e matemáticos e, por isso, têm dificuldades em articular os conhecimentos das diferentes áreas. E isso pode ser um obstáculo para a articulação dos conhecimentos científicos, tão importantes para a compreensão do dia a dia do aluno. 
Ao desenvolver a problematização, os licenciandos se limitavam a perguntas diretivas, como manifestado em suas falas. Entendemos que não é demérito fazer perguntas diretivas. Mas dentro da problematização, proposta em um contexto de inovação, a questão precisaria ser mais complexa, não "complicada", mas no sentido de desafiar o aluno, a ponto de provocar incertezas e dúvidas de seus conhecimentos ingênuos e, então, promover rupturas que permitam a construção de conhecimentos mais críticos e elaborados.

Pensar complexo, aqui no sentido de construir uma problematização, não é rejeitar e desprezar uma simples pergunta, como dito anteriormente, mas, sim, criticar sua simplificação, como coloca Morin, Ciurana e Motta (2003, p. 58): o “[...] pensamento complexo não rejeita o pensamento simplificador, mas reconfigura suas consequências através de uma crítica a uma modalidade de pensar que mutila, reduz, unidimensionaliza a realidade". Dessa forma, uma simples pergunta, muitas vezes diretiva, leva os alunos a responderem mecanicamente aquilo que já sabem, apenas resgatando as informações que já tenham guardado na memória.

Assim como manifestado pelos licenciandos, Carvalho (2012, p. 23) diz que é "[...] difícil mudar esses tipos de questões para perguntas que levam o aluno a raciocinar", dado que são mais longas e complexas, pela natureza dos conteúdos que as compõem. Ademais, perguntas diretivas não evocam o diálogo, pelo contrário, cultivam o monólogo, já que questionamentos mais abertos e indiretos permitem a interação entre o professor, aluno, conteúdo e ambiente (CARVALHO, 2012). Sem essa interação, o professor não tem como questionar os posicionamentos, lançar dúvidas e nem fomentar o debate das respostas manifestadas pelos alunos, aspectos tão almejados na problematização.

Percebemos, algumas vezes, que os sujeitos apresentavam resistências ao construir uma situação problematizadora, pelo fato de exigir mais estudo e pesquisa, como consta na seguinte fala: " $\mathrm{Na}$ aula de hoje, tive a compreensão da necessidade de aprofundar meus conhecimentos para questionar os alunos em relação ao meu tema para a problematização" (DANI). Nesse sentido, pensamos que não tem como problematizar um tema sem conhecê-lo com maior profundidade. E mais, a "[...] falta de conhecimentos científicos constitui a principal dificuldade para que os professores afetados se envolvam em atividades inovadoras" (CARVALHO; GIL-PEREZ, 2011, p. 22).

Presumimos também que as dificuldades em compreender e elaborar a problematização, retratada pelos licenciandos, estão intimamente relacionadas ao impasse do pensar multidimensional, o que de certa forma pode ser herança de uma tradição do ensino pautado na racionalidade técnica, que supervaloriza o uno em detrimento do múltiplo e do interdisciplinar. Alguns alunos chegam a reconhecer isso, a saber:

[...] para mim, está sendo crucial, pois quem, em todo seu universo escolar, veio de um modelo tradicionalista e conteudista, confesso estar tendo uma série de dificuldades em fazer esta exposição [...] no entanto, vejo uma luz no final do túnel, para quem não estava entendo nada [...] acho esta nova forma de abordagem do conhecimento bem diferenciada e contextualizada (BARBARA). 
Tive inúmeras dificuldades, pois ainda estou muito atrelada ao ensino tradicional. É muito difícil pensar e construir outra forma de ensinar. E a problematização foi um problema (FABÍOLA).

Essa vinculação ao que eles chamam de tradicional pode sim estar contribuindo para a configuração dos entraves mencionados. Alguns traços característicos desse ensino é a formação exclusivamente disciplinar, na qual o conhecimento é apresentado como saber simplificado, estático, acabado e absoluto (POZO; CRESPO, 2009). Alguns professores enxergam um mundo de simplificações e, por isso, acreditam que ser didático é simplificar o conhecimento (NASCIMENTO, 2012), assim como acontece com os sujeitos ao elaborar uma pergunta meramente diretiva.

No contexto incerto e diversificado que se constitui a educação do século XXI, não há mais espaço para práticas pedagógicas pautadas na transmissão de conhecimentos fragmentados e compartimentalizados (IMBERNON, 2011). Além do mais, essas não possuem potencial capaz de instrumentalizar intelectualmente os futuros professores para elaborarem questões que promovam um conflito cognitivo e desperte uma curiosidade epistemológica em seus futuros alunos. Tal conclusão emerge dos próprios alunos, já que eles reconhecem que essas limitações são obstáculos para desenvolver a proposta de problematização.

\section{ORGANIZAÇÃO DO CONHECIMENTO: AMARRAS DE UMA VISÃO SIMPLISTA DO ENSINO DE CIÊNCIAS}

É nesse MP que os conhecimentos científicos, necessários para a compreensão dos assuntos problematizados são sistematicamente estudados (GEHLEN; MALDANER; DELIZOICOV, 2012). E foi ao organizar a sequência didática que compõe esse MP, na etapa de Construção do Roteiro de Aula, que os alunos se depararam, novamente, com outros obstáculos, como manifestado nas seguintes falas:

Senti uma dificuldade enorme em como sair do tradicional, por mais que acreditasse que estava me desvinculando desse método uma hora percebia que não estava tanto (LUíS).

Mas eu tive dificuldades. [Apresentava] atividades prontas, tradicionais, por que junto com os alunos, eu queria construir as respostas, responder as perguntas com eles (FLORA).

As dificuldades indicadas relacionam-se ao fato de os licenciandos se reconhecerem, ainda, como tradicionais. No momento em que iam desenvolvendo esse MP, percebia-se, sim, que as propostas limitavam-se, por vezes, a visões simplistas de ensino. A organização do conhecimento se dava por meio de aulas expositivas, carregadas de conceitos científicos específicos, juntamente com exercícios de "fixação" de conteúdo. Mesmo quando traziam recursos e atividades diferenciadas, eles não exploravam todo potencial pedagógico das mesmas.

Ao nos depararmos com essas propostas, buscávamos provocar os alunos, na intenção de que eles analisassem criticamente suas escolhas. Por vezes questionávamos: "se fossem vocês assistindo essa aula, achariam interessante? Vocês se envolveriam nas atividades?" As respostas quase sempre eram: "de fato, precisa melhorar"; "não tá legal!". 
Acreditamos que as resistências e as dificuldades dos sujeitos não estão no simples fato de assim desejarem ser, mas, sim, decorrentes de experiências formativas vividas ainda quando alunos, que os instrumentalizaram, mesmo que inconscientemente, constituindo-se, assim, o que Carvalho e Gil-Pérez (2011) denominam de pensamento docente espontâneo ou formação ambiental. Esses autores colocam ainda que tais experiências influenciam significativamente na prática pedagógica do futuro professor, por serem adquiridas "[...] de forma não reflexiva como algo natural ou óbvio, o chamado 'senso comum', escapando assim a critica e transformando-se em um verdadeiro obstáculo" (CARVALHO; GILPÉREZ, 2011, p. 28), o que no nosso entender, também, para a inovação.

Nesse sentido, Tardif (2013, p.20) coloca que

Antes mesmo de ensinarem, os futuros professores vivem nas salas de aula e nas escolas e, portanto, seu futuro local de trabalho - durante aproximadamente 16 anos (ou seja, em torno de 15.000 horas). Ora, tal imersão é necessariamente formadora, pois leva os futuros professores a adquirirem crenças representações e certezas sobre a prática do ofício de professor, bem como sobre o que é ser aluno. Em suma, antes mesmo de começarem a ensinar oficialmente, os professores já sabem, de muitas maneiras, o que ensinar por causa de toda a sua história escolar anterior.

Assim, o apego dos futuros professores às práticas docentes mobilizadas por essa formação é forte e justificável, mas não aceitável já que as amarras na formação docente não constituem nenhum obstáculo insuperável. Os “"[...] diferentes problemas podem ser abordados e resolvidos por equipes docentes em um processo criativo e satisfatório [de formação]" (CARVALHO; GIL-PÉREZ, 2011, p. 30-31).

No contexto da inovação didática, tal obstáculo formativo dificulta a nossa capacidade de renovação do ensino já que, uma vez cristalizado, torna-se muito mais difícil mudar a didática e a epistemologia do ensino e da aprendizagem (CARVALHO; GIL-PÉREZ, 2011; CACHAPUZ; CARVALHO; GIL-PÉREZ, 2012). No entanto, os sujeitos precisam estar abertos às mudanças, visto que a libertação das amarras necessita de uma ruptura pessoal, por dentro, para, então, instaurar uma nova forma de agir e pensar (FARIAS, 2006).

Outro impasse na elaboração desse momento estava no fato de os futuros professores não valorizarem os conhecimentos prévios dos alunos, que poderiam ser manifestados na Problematização Inicial, visto que na elaboração dos roteiros de aula, foram poucas as equipes que partiram de possíveis repostas das questões problematizadas. O ponto de partida muitas vezes era a ordem como o livro didático apresenta o tema. A questão é que esses "manuais" não devem ser seguidos como um livro de receitas e ser um obstáculo para inovação, uma vez que não incentivam o professor a criar sua própria sequência didática, exercendo a liberdade de escolher "o que", "quando" e "como" melhor desenvolver sua aula.

Mas uma questão que se revelou obstáculo foi a seleção dos conteúdos, apesar de termos norteado esta seleção por meio de uma ementa descritiva, que anunciava as possibilidades quanto aos conteúdos a serem trabalhados. As falas das alunas abaixo ilustram esse entrave, quais sejam: 
Aqui [2MP] a dificuldade foi em selecionar o conteúdo, saber o que ensinar, levando uma proposta inovadora a qual não deixasse com que o aluno ficasse parado, sentado, como sujeito passivo. Foi pensando em aulas mais práticas e dinâmicas, onde o aluno tivesse ferramentas para responder os questionamentos, as hipóteses surgidas no 1MP (TAIANA).

[Tive dificuldades em] organizar e selecionar os conteúdos mais importantes, a ser trabalhado, buscar formas de ensinar que motive o aluno tornando-o participativo e tentar sair do método tradicional no qual só o professor detém todo o conhecimento (SOPHIA).

A dificuldade maior foi a falta de domínio sobre o assunto, foi preciso bastante pesquisa, leituras e discussões para desenvolvermos o segundo momento pedagógico (DANI).

Aqui notamos que assim como no primeiro MP, os licenciandos não tinham muita compreensão do assunto a ser trabalhado, como destacado por Dani. Por vezes, notávamos que os sujeitos não se envolviam com entusiasmo e compromisso nas pesquisas e nos estudos sobre os conteúdos, para então poder construir as situações de ensino e de aprendizagem no roteiro de aula.

Saber somente a matéria a ser ensinada é insuficiente, mas o seu conhecimento é imprescindível para o ato de ensinar (IMBERNÓN, 2012), tal qual é para saber eleger conteúdos que tenham potencial de desenvolver nos educandos capacidades motoras, cognitivas, afetivas, de relação pessoal e também de inserção social, assim como orienta Zabala (2010). Portanto, entendemos que é importante, enquanto professores, realizarmos os estudos de forma mais compromissada, visto que não é apenas a nossa formação que está em jogo, mas também a de nossos alunos.

Então, conhecedores dos conteúdos ligados ao tema, os professores terão melhor chance de conseguir, como admitiu uma discente, de organizar e de dirigir situações de ensino e de aprendizagem, a saber:

[...] a partir do momento que o professor se prepara [...] sobre o assunto que irá trabalhar com seus alunos, pelo que entendi, é mais fácil organizar o conhecimento [...] (MEL).

Isso ocorre pelo fato de que a posse de "mais" conhecimentos nos permite "[...] imaginar e criar outros tipos de situações de aprendizagem, que as didáticas contemporâneas encaram como situações amplas, abertas e carregadas de sentido [...]" (PERRENOUD, 2000, p. 25-26), assim como tanto se almeja para o segundo MP.

No sentido de apresentar situações de ensino e de aprendizagem significativas, algumas discentes (Taiana e Sophia) mostraram preocupação e dificuldades em encontrar "formas de ensinar", ou seja, estratégias de ensino capazes de envolver o aluno em uma ação mais participativa, estimulando o diálogo, integrando conhecimentos, para, então, permitir uma leitura crítica da realidade, assim como orienta Muenchen (2010).

Ao desenvolver o segundo MP, o professor pode fazer uso de diversas estratégias de ensino, como seminários, estudos em grupo, excursões, visitas, encenações teatrais, debates, entre outras; inclusive, podendo variar em objetivo, complexidade e custo (SOUZA; IGLESIAS; PAZIN-FILHO, 2014). É relevante reconhecer que as 
estratégias de ensino constituem-se "[...] um passo, talvez indispensável, para atingir melhor a capacidade de raciocínio, de pensamento criativo e de resolução de problemas no estudo dos conteúdos escolares" (LIBÂNEO, 2011, p. 37).

Ao fazer uso, por exemplo, de atividades investigativas, o professor pode contribuir justamente para o que anseia a discente (Taiana), que é a participação dinâmica e ativa dos alunos, na qual os mesmos tenham ferramentas para responder os questionamentos, hipóteses, que surgiram na problematização. Além do mais, orientações investigativas contribuem para a inovação, já que na concepção de Azevedo (2009), elas seguem uma perspectiva renovadora do ensino de ciências. É interessante, também, que os alunos continuem sendo confrontados com problemas e controvérsias, forçando-os à reflexão crítica do que lhes é posto, estimulando suas potencialidades, suas múltiplas inteligências e suas diversas formas de aprender.

Acreditamos que as dificuldades dos licenciandos em escolher e desenvolver essas estratégias podem estar relacionadas com o próprio perfil do curso de Licenciatura Integrada. Nele, não há um Tema específico destinado ao trabalho de estratégias para o ensino, como é comum em outros cursos de licenciatura. No Curso, os alunos têm contato com atividades didáticas e pedagógicas diversificadas, ao longo de todos os Eixos Temáticos (PROJETO, 2012).

Pensamos que por estarem cursando ainda o terceiro semestre do curso, os alunos tiveram poucas oportunidades de vivenciar e de incorporar metodologias de ensino mais ativas, próprias do Curso, como estudos de casos, oficinas, minicursos, resolução de problemas, entre muitas outras. Isso, de certa forma, reflete na pouca "instrumentalização" dos sujeitos e em suas dificuldades em pensar "a forma" do ensino.

Fato é que proporcionar aos futuros professores vivências com estratégias inovadoras, propicia aos alunos e ao seu formador "[...] a possibilidade de repensar a prática docente para um ensino de melhor qualidade, e essa está atrelada ao desenvolvimento de novos saberes para um crescimento pessoal e profissional" (SANTOS; SILVA; ARAÚJO, 2012, p. 11). Desse modo, espera-se que até o final do Curso, vivenciando experiências como essas, eles tenham mais desenvoltura para planejar atividades que contemplem estratégias diferenciadas, tecendo aulas inovadoras, com potencial de incentivar o pensamento crítico e de estimular outras formas de conhecer e de ensinar (BORGES; TAUCHEN, 2012).

Apesar de poucos licenciandos relatarem, percebemos nas etapas de Construção do Roteiro de Aula e de Socialização, que eles apresentavam dificuldades em contemplar a construção de conhecimentos procedimentais e atitudinais, como é observado na seguinte fala:

[Tive dificuldades de] dar os assuntos sem que fique muita informação [no sentido de conteúdo conceitual] e fazer com que eles aprendam de verdade não só decorem momentaneamente (JAMILA).

Situação essa que pode ter múltiplas origens, desde a questão da formação ambiental até os impasses de pensar a complexidade. E, por isso, sempre buscávamos orientá-los na perspectiva de alçarem voos para além do saber conceitual, a fim de 
privilegiarem, também, a natureza do "saber fazer" e do "saber ser". A natureza complexa desses conteúdos é o primeiro entrave para que sejam contemplados no planejamento de aula de muitos professores, a começar pelos conteúdos procedimentais, que apesar de terem um denominador comum, o "saber fazer", possuem componentes motores e cognitivos que apresentam peculiaridades tanto no seu ensino como na sua aprendizagem (ZABALA, 2010).

Por essa heterogeneidade, não basta realizar uma única vez as ações de um determinado procedimento, é necessário exercitá-lo, preferencialmente, em contextos diferenciados, para, então, permitir maior reflexão sobre o que é ensinado (ZABALA, 2010). No entanto, “[...] é preciso ter um conhecimento significativo dos conteúdos conceituais associados ao conteúdo procedimental que se exercita ou se aplica" (ZABALA, 2010, p.46).

Já os conteúdos referentes às atitudes são, possivelmente, os de mais difícil abordagem, dado que tanto a formação quanto a disposição dos professores é menos voltada "[...] para ensinar seus alunos a comportarem-se na aula, a cooperar e ajudar seus colegas ou, inclusive, a descobrir o interesse pela ciência como forma de conhecer o mundo que nos rodeias" (POZO; CRESPO, 2009, p. 29). Infelizmente, as atitudes configuram-se como as principais dificuldades para o ensino e a aprendizagem das ciências, como ilustra Pozo e Crespo (2009, p. 31), com sua interessante ponderação, a saber:

\footnotetext{
Como os gases, as atitudes tendem a ser onipresente, mas ausente de nossos sentidos, e se misturam umas às outras - e, por isso, não é possível cortá-las, nem separá-las facilmente -, mas não estão em nenhumas, por isso são tão difíceis de perceber (avaliar). [...]. As atitudes, na medida em que, como os gases, são dificilmente fragmentáveis, exigem um trabalho contínuo, mas de longo prazo.
}

Entretanto, entendemos que as dificuldades em organizar conhecimentos referentes aos conteúdos procedimentais e atitudinais não são únicos e exclusivamente dos sujeitos aqui acompanhados. A questão está justamente na natureza complexa desses conteúdos, o que exige de nós maior exercício do pensamento complexo.

\section{APLICAC̣ÃO DO CONHECIMENTO: HERANC̣AS DE UM AVALIAR PONTUAL FINALÍSTICO}

Ao longo dos encontros, buscávamos sempre chamar a atenção dos licenciandos para o seguinte fato: a Aplicação do Conhecimento não diz respeito a um momento avaliativo em si, visto que a avaliação, no contexto dos $3 \mathrm{MPs}$, é concebida como um processo integrador, e não como um resultado pontual e finalístico das situações de aprendizagem, assim como na concepção de Zabala (2010). Portanto, a avaliação deve ser desenvolvida durante todos os três momentos da proposta didática.

O terceiro MP, mais um componente desse processo, tem por finalidade "[...] empregar o conhecimento do qual o estudante vem se apropriando para analisar e interpretar a compreensão do mesmo sobre as situações" (GEHLEN; MALDANER; DELIZOICOV, 2012, p. 12), tanto aquelas problematizadas como outras que emergiram durante o processo. Entre os momentos pedagógicos esse 
foi o que menos mobilizou conflitos formativos, como revela uma discente: "[...] dentre os três momentos, o que encontramos menos dificuldades foi no terceiro momento [...]" (DANI). Todavia, esse $3^{\circ} \mathrm{MP}$ ainda inquietou muitos alunos, uma vez que poucos sabiam como construir uma situação que envolvesse ativamente os alunos na aplicação dos conhecimentos construídos.

De início, pensamos que os sujeitos tivessem conseguido romper com a compreensão do terceiro MP como avaliação finalística. No entanto, nos deparamos com atividades distantes da que esperávamos. Nesse instante, mais dúvidas e incertezas emergiram, configurando novamente outra tensão formativa.

Ao término da elaboração dos roteiros, os licenciandos reconheciam as insuficiências de suas propostas, e relatavam que não conseguiam fazer/criar diferente. Limitaram-se, novamente, a atividades diretivas de memorização e de reprodução do conhecimento, características de avaliações de um modelo seletivo e propedêutico (ZABALA, 2010). Os excertos abaixo ilustram isso:

$\mathrm{Na}$ hora de aplicar o conhecimento, tivemos dificuldades para escolher atividades que fossem adequadas e não tradicionais para o planejamento [...] (LUANA).

É difícil inovar, eu estou acostumada, com aquelas atividades de fixação, e somente responder várias questões, então foi muito difícil romper com essas raízes e criar formas novas de aplicar o conhecimento aos alunos (MEL).

A afiliação a atividades, como as mencionadas, é, de certa forma, uma reprodução de velhos hábitos da educação, tão entranhados no sistema escolar e no próprio professor, de difícil superação e rupturas. Desse modo, os resquícios da formação espontânea, ingênua e acrítica dos sujeitos, revelaram-se, novamente, um entrave para a criação de propostas mais interessante e com maior potencial pedagógico, no campo da inovação.

Percebendo esses impasses, buscamos intervir novamente orientando as equipes. Nos encontros com os grupos, buscávamos discutir sobre as diversas possibilidades para aplicar o conhecimento do tema que eles estavam desenvolvendo. Dentre a multiplicidade de estratégias, focamos naquelas situações abertas, algumas conflitivas, outras investigativas e, principalmente, aquelas grupais, por considerar, assim como Imbernón (2012, p. 20), que elas

[...] têm muitas vantagens, como o incentivo e a motivação ao trabalho, o aumento da criatividade, a possibilidade de análise dos pontos de vista diferentes, o desenvolvimento da capacidade de cooperação e promoção de troca de experiências. [Além do mais, trabalhar] em grupo implica aprender a dialogar, a se comunicar, a chegar a um acordo, a ceder a palavra ao outro, a trabalhar um projeto comum a muitos dos componentes do sujeito ativo da sociedade do futuro. A desenvolver competências transversais.

Características essas que transitam tanto na proposta dialógica e problematizadora dos $3 \mathrm{MPs}$, como na concepção de estratégias inovadoras de ensino de ciências nas séries iniciais. Seguindo essa ponderação de Imbernón (2012), apresentamos algumas das atividades que consideramos ter potencial significativo 
para Aplicação do Conhecimento: estudo de caso, debates, elaboração de cartas abertas a autoridades, experimentação, entre outras.

Conhecedores das possibilidades apresentadas, algumas equipes chegaram a iniciar o planejamento de algumas atividades. Mas, ao longo do processo de criação, ao perceber novamente as dificuldades, foram desistindo. Foi então que questionamos: "Vocês estavam indo tão bem! Porque desistiram?" Em resposta, ouvimos: "é muito difícil ser diferente, é mais fácil ser tradicional".

De fato, é mais fácil, sim, ser tradicional! Mas, atualmente, não há espaço para práticas anacrônicas, ou seja, “[...] hoje, não tem mais sentido a existência de um profissional que se limita a reproduzir o conhecimento e a cultura que os outros desenvolveram. O professor de hoje precisa ser capaz de criar conhecimento" (GADOTTI, 2011, p. 31, destaque nosso).

Nesse sentido, concordamos com Nóvoa (1999, p. 20), que ao pensar na formação de futuros professores, refere que não podemos seguir "[...] sem calar a indignação pelo estado atual das coisas”. Assim, seguimos na tentativa de inovar e de mudar tal estado, entendendo que isso é um processo doloroso e lento, já que, assim como na educação, ninguém muda de imediato. Como afirma Imbernón (2011, p. 14), a “[...] pessoa precisa interiorizar, adaptar e experimentar os aspectos novos que viveu em sua formação”. Logo, esperamos que as novas experiências, mesmo que conflitivas, vividas pelos sujeitos em cada MP, contribua para a inovação didática, que tanto acreditamos ser possível.

Por fim, destacamos que o fato dos licenciandos estarem cursando o terceiro semestre do curso é significativo para a tensão protagonizada, visto que viviam um processo inicial da formação - etapa em que estão mais impregnados por saberes docentes da experiência. Desse modo, tais saberes, construídos ainda quando alunos, podem ter possibilitado maior resistência, dificultando rupturas, configurando desafios para a formação.

\section{CONSIDERAC̦ÕES FINAIS}

Consideramos que a experiência com os Três Momentos Pedagógicos se configurou inovadora na formação desses sujeitos, visto que os mesmos se (re)criaram ao longo da experiência, a qual sem dúvida provocou, se não em todos, mudanças no pensar e no fazer docente. Se tratando de inovação didática, entendemos que o importante não é a chegada ao "pódio", mas, sim, a ação de partir. Nesse sentido, caminhar em direção à inovação representa a tentativa de romper com a inércia que tanto toma conta do cenário educacional. O percurso de recriação dos sujeitos envolvidos no aventurar inovador é tão mais relevante quanto o "aonde chegar".

No percurso da aventura inovadora que propomos aos sujeitos envolvidos, fomos percebendo significativos entraves que impediam a partida. Primeiro, os alunos não compreendiam a Problematização Inicial, apresentando dificuldades em problematizar um tema - chegando até a tornar-se um "problema a tal problematização". Segundo, apresentavam dificuldades em abandonar as aulas tradicionais que tanto criticavam, não conseguindo elaborar ideias mais integradoras, que se configurassem, no mínimo, interessante para o desenvolvimento da 
Organização do Conhecimento. Terceiro, não conseguiam superar as amarras de uma avaliação pontual e finalística, na elaboração de atividades para a Aplicação do Conhecimento, limitando-se em exercícios fechados de memorização e fixação.

Entendemos tais entraves como sendo fruto de saberes docentes construídos no período em que esses sujeitos aprendiam e aprendem a ser professor quando alunos, herdando hábitos, valores e saberes tão enraizados que se configuram em significativos obstáculos para a formação, notadamente para inovação didática. Por outro lado, reconhecemos que não há receitas, regras ou modelos prontos para a superação de tais obstáculos, mas é fato que não se trata de nenhum problema intransponível na formação de professores.

Foi vivenciando todos esses conflitos, dificuldades e tensões, que consideramos o processo formativo como uma experiência problematizadora da docência, capaz de contribuir para a edificação de saberes necessários a uma reconstrução teórica, didática e epistemológica do fazer e do ser professor nos tempos de hoje. Por fim, acreditamos que vivenciar propostas inovadoras de ensino pode romper com a visão estática e firmada do mesmo, proporcionando o permanente movimento de cristalização e de dissolução de concepções de docência. Decerto, oportunizando que tais propostas passem a ser "tão naturais e comuns" quanto às vivenciadas até o momento.

\section{REFERÊNCIA}

AZEVEDO, R. O. M. Ensino de Ciências e formação de professores: diagnóstico, análise proposta. 2009. 165 f. Dissertação (Mestrado Profissional em Ensino de Ciências na Amazônia). Universidade do Estado do Amazonas, Manaus, Amazonas, 2009.

BARBIER, R. A pesquisa-ação. Brasília: Liber Livro Editora, 2007.

BORGES, D. S; TAUCHEN, G. Inovações no ensino universitário: possibilidades emergentes. Educação. Santa Maria, v. 37, n. 3, p. 555-568, 2012.

CACHAPUZ, A. ; CARVAlHo, A. M. P. ; PÉREZ, D. G. (org.). O ensino das ciência como compromisso científico e social: os caminhos que percorremos. $1^{a}$ ed. São Paulo, Cortez, 2012.

CARVAlHO, A. M. P de. Os estágios nos cursos de licenciatura. $1^{\mathrm{a}}$ ed. São Paulo: Cengage Learning, v. 1, 2012.

CARVALHO, A. M. P de; GIL-PEREZ, D. Formação de professores de ciências: tendências e inovações. 10a ed. São Paulo: Cortez, 2011.

CHASSOT, Á. I. Alfabetização científica: questões e desafios para a educação. $5^{a}$ ed. Ijuí, RS: Ed. UNIJUÍ, 2011.

DELIZOICOV, D. Os três momentos pedagógicos e o contexto de produção do livro "Física". Ciência \& Educação, Bauru, v. 20, n. 3, p. 617-638, 2014.

DELIZOICOV, D. Problemas e Problematizações. In: PIETROCOLA, M. (org.). Ensino de física? Conteúdo, metodologia e epistemologia numa concepção integradora. Florianópolis: Ed. da UFSC, 2001. p. 125-150.

DELIZOICOV, D.; ANGOTTI, J. A. Metodologia do ensino de ciências. São Paulo: Cortez, 1990.

Delizoicov, D.; ANGOTTI, J. A A.; PERnAmbuCO, M. M. C. A. Ensino de ciências: fundamentos e métodos. $3^{a}$ ed. São Paulo: Cortez, 2002. (Docência em formação: Ensino fundamental). FARIAS, I. M. S de. Inovação, mudança \& cultura docente. Brasília: Liber Livros, 2006. 
FRAIHA-MARTINS, F. Significação do ensino de ciências e matemática em processos de letramento científico-digital. 2014, 190f. Tese (Doutorado em Educação em Ciências e Matemática). Universidade Federal do Pará. Pará, Belém, 2014.

GADOTTI, M. A boniteza de um sonho: ensinar-e-aprender com sentido. $2^{a}$ ed. São Paulo: Editora e Livraria Paulo Freire, 2011,

GEHLEN, S. T.; MALDANER, O. A.; DEMÉTRIO, D. Momentos pedagógicos e as etapas da situação de estudo: complementos e contribuições para a educação em Ciências. Ciência \& Educação, Bauru - SP, v.18, n.1, p. 1-22, 2012.

GENTILINI, João A.; SCARLATTO, Elaine Cristina. Inovações no ensino e na formação continuada de professores: retrocessos, avanços e novas tendências. In: PARENTE, C. da M. D.; VALLE, L. E. R. do; MATTOS, M. J. V. M. de (org.). A formação de professores e seus desafios frente às mudanças sociais, políticas e tecnológicas. Porto Alegre: Penso, 2015, p. 15-40.

HARGREAVES, A. Os professores em tempos de mudança. Alfragide, Portugal: McGraw-Hill, 1998. Resenha de ALBERTANI, Helena Maria Becker. Revista Brasileira de Educação. n.12, p.105-108, 1999.

IMBERNÓN, F. Inovar o ensino e aprendizagem na Universidade. São Paulo: Cortez, 2012.

IMBERNÓN, F. Formação docente e profissional: formar-se para a mudança e a incerteza. $9^{a}$ ed. São Paulo: Cortez, 2011.

JOSSO, M. C. Experiências de vida e formação. $2^{a}$ ed. RN: EDUFRN; São Paulo: Paulus, 2010. KUHN, T. S. A estrutura das revoluções científicas. $10^{\mathrm{a}}$ ed. São Paulo: Editora Perspectiva S.A, 2011. LIBÂNEO, J. C. Adeus professor, adeus professora? Novas exigências educacionais e profissão docente. $13^{a}$ Ed. São Paulo: Cortez, 2011.

MARENGÃO, L. S. L. Os três momentos pedagógicos e a elaboração de problemas de física pelos estudantes. 2012, 82f. Dissertação (Mestrado em Educação em Ciências e Matemáticas). Universidade Federal do Goiás. Goiás, Goiânia, 2012.

MATOS, I. P. A. Inovação educacional e formação de professores: em busca da ruptura paradigmática. 2010, 183f. Dissertação (Mestrado em Educação). Universidade Federal de Goiás. Goiás, Goiânia, 2010.

MINAYO, M. C. de S. O desafio da pesquisa social. In: MINAYO, M. C. de S (org.). Pesquisa social: teoria, método e criatividade. $27^{\mathrm{a}}$ ed. Petrópolis, RJ: Vozes, 2016. p. 9-28.

MORAES, R. Mergulhos discursivos: análise textual qualitativa entendida como processo integrado de aprender, comunicar e interferir em discursos. In: GALIAZZI, M. C.; FREITAS, J. V. Metodologias emergentes de pesquisa em educação ambiental. Ijuí: Unijuí, 2007. p. 85-114.

MORAES, R.; GALIAZZI, M. do C. Análise textual discursiva. Ijuí: Unijuí, 2007. 224 p.

MORIN, E. O desafio do século XXI: religar os conhecimentos. Lisboa: Instituto Piaget, 2001.

MORIN, E.; CIURANA, E. R.; MOTTA, R. D. Educar na era planetária: o pensamento complexo como método de aprendizagem pelo erro e incerteza humana. São Paulo: Cortez; Brasília: UNESCO, 2003.

MUENCHEN, C. A disseminação dos três momentos pedagógicos: um estudo sobre práticas docentes na região de Santa Maria/RS.2010. 213 f. Tese (Doutorado em Educação Científica e Tecnológica). Universidade Federal de Santa Catarina. Santa Catarina, Florianópolis, 2010.

MUENCHEN, C.; DELIZOICOV, D. A construção de um processo didático-pedagógico: aspectos epistemológicos. Revista Ensaio, Belo Horizonte, v. 14, n. 3, p.199-215, 2012.

MUENCHEN, C.; DELIZOICOV, D Concepções sobre a problematização na educação em ciências. IX Congresso Internacional sobre Investigación em Didáctica de las Ciências. Girona: Espanha, p. 2447-2451, 2013.

NASCIMENTO, P. L. Edgar Morin: seu pensamento transdisciplinar e a educação planetária. 
2012. Revista Online de Iniciativa do Portal do Professor, do MEC. Disponível em: < https:// transdisciplinaridade.wordpress.com/2012/07/20/edgar-morin-seu-pensamento-transdisciplinar-ea-educacao-planetaria/>. Acesso em: 24 fev. 2016.

NÓVOA, A. Os professores na virada do milênio: do excesso dos discursos à pobreza das práticas. Educação e Pesquisa, São Paulo, v. 25, n. 1, p. 11-20, 1999.

PERRENOUD, P. 10 novas competências para ensinar. Porto Alegre: Artmed, 2000.

POZO, J. I. ; CRESPO, M. G. Á. A aprendizagem e o ensino de ciências: do conhecimento cotidiano ao conhecimento científico. $5^{\text {a }}$ ed. Porto Alegre: Artmed, 2009.

PROJETO Pedagógico do Curso de Licenciatura Integrada em Educação em Ciências, Matemática e Linguagens, do Instituto de Educação Matemática e Científica (IEMCI). Belém: Universidade Federal do Pará, 2010.

ROSA, C. W. da; PEREZ, C. A. S.; DRUM, C. Ensino de física nas séries iniciais: concepções da prática docente. Investigações em Ensino de Ciências, Rio Grande do Sul, v.12, n. 3, p.357-368, 2007.

SANTOS, C. N. P. dos; SILVA, R. P. da; ARAÚJO, M. L. F. Contribuições de estratégias didáticopedagógicas inovadoras para o ensino da biologia. VI Colóquio Internacional "Educação e contemporaneidade". São Cristovão, SE, 2012. Anais eletrônicos... Disponível em: <http:// educonse.com.br/2012/eixo_06/PDF/27.pdf>. Acesso em: 12 fev. 2016.

SOUZA, C. da S.; IGLESIAS, A. G.; PAZIN-FILHO, A. Estratégias inovadoras para métodos de ensino tradicionais: aspectos gerais. Medicina, Ribeirão Preto, v. 47, n. 3, p. 284-92, 2014.

TARDIF, M. Saberes docentes e formação profissional. 14ª ed. Petrópolis, RJ: Vozes, 2013.

VIECHENESKI, J. P.; LORENZETTI, L.; CARLETO, M. R. Desafios e práticas para o ensino de ciências e a alfabetização científica nos anos iniciais do ensino fundamental. Atos de Pesquisa em Educação, Blumenau, Santa Catarina, v. 7, n. 3, p. 253-876, 2012.

ZABALA, A. A prática educativa: como ensinar. $2^{\mathrm{a}}$ ed. Porto Alegre: Artmed, 2010.

\section{NOTAS}

${ }^{1}$ São seis os eixos que compõem o currículo do Curso, segundo o PPC: Aquisição de Leitura e Escrita; Teoria e Prática Docente em Ciências e Matemática; Processos de Ensino e Aprendizagem em Ciências, Matemática e Linguagens; Ciência, Tecnologia, Sociedade e Ambiente; Construção de Conceitos e Uso de Linguagens em Ciências e Matemática; e Estágios de Docência.

${ }^{2}$ Ementa do tema: aprofundamento teórico e metodológico de assuntos relativos aos anos iniciais de ensino fundamental para propor e produzir materiais e realizar atividades de ensino mediadas pela pesquisa da área. Realização de práticas de situações reais e simuladas envolvendo estudantes de educação básica, professores dos anos iniciais e comunidade. Discussão e avaliação das atividades realizadas e sua contribuição para o processo de ensino e aprendizagem. Ênfase em ciências e suas relações com a alfabetização matemática, digital e da língua materna.

Submetido em 28/06/2016

Aprovado em 08/09/2017

\section{Contato:}

Josyane Barros de Abreu

Programa de Pós-Graduação em Educação em Ciências e Matemáticas (Doutoranda)

Rua Augusto Corrêa, 01 - Bairro Guamá, Belém, Pará, Brasil

CEP 66075-110

Email: josyanebarros@gmail.com 